\title{
Quantifying seasonal and diel variation in Anopheline and Culex human biting rates in Southern Ecuador
}

Sadie J. Ryan ${ }^{1,2,3,4^{*}} \mathbb{D}$, Catherine A. Lippi ${ }^{1,2^{*}} \mathbb{C}$, Philipp H. Boersch-Supan ${ }^{1,2,5} \mathbb{0}$, Naveed Heydari ${ }^{3}$, Mercy Silva ${ }^{6}$, Jefferson Adrian ${ }^{3}$, Leonardo F. Noblecilla ${ }^{7}$, Efraín B. Ayala ${ }^{8}$, Mayling D. Encalada ${ }^{9}$, David A. Larsen ${ }^{10}$, Jesse T. Krisher ${ }^{11}$, Lyndsay Krisher ${ }^{12,13}$, Lauren Fregosi ${ }^{1,10}$ and Anna M. Stewart-Ibarra ${ }^{3}$ (D)

\begin{abstract}
Background: Quantifying mosquito biting rates for specific locations enables estimation of mosquito-borne disease risk, and can inform intervention efforts. Measuring biting itself is fraught with ethical concerns, so the landing rate of mosquitoes on humans is often used as a proxy measure. Southern coastal Ecuador was historically endemic for malaria (Plasmodium falciparum and Plasmodium vivax), although successful control efforts in the 2000s eliminated autochthonous transmission (since 2011). This study presents an analysis of data collected during the elimination period.

Methods: Human landing catch (HLC) data for three mosquito taxa: two malaria vectors, Anopheles albimanus and Anopheles punctimacula, and grouped Culex spp. were examined for this study. These data were collected by the National Vector Control Service of the Ministry of Health over a 5-year time span (2007-2012) in five cities in southern coastal Ecuador, at multiple households, in all months of the year, during dusk-dawn (18:00-6:00) hours, often at both indoor and outdoor locations. Hurdle models were used to determine if biting activity was fundamentally different for the three taxa, and to identify spatial and temporal factors influencing bite rate. Due to the many different approaches to studying and quantifying bite rates in the literature, a glossary of terms was created, to facilitate comparative studies in the future.

Results: Biting trends varied significantly with species and time. All taxa exhibited exophagic feeding behavior, and outdoor locations increased both the odds and incidence of bites across taxa. Anopheles albimanus was most frequently observed biting, with an average of 4.7 bites/h. The highest and lowest respective months for significant biting activity were March and July for An. albimanus, July and August for An. punctimacula, and February and July for Culex spp.

Conclusions: Fine-scale differences in endophagy and exophagy, and temporal differences among months and hours exist in biting patterns among mosquito taxa in southern coastal Ecuador. This analysis provides detailed information for targeting vector control activities, and household level vector prevention strategies. These data were collected as part of routine vector surveillance conducted by the Ministry of Health, and such data have not been collected since. Reinstating such surveillance measures would provide important information to aid in preventing malaria re-emergence.
\end{abstract}

Keywords: Anopheles albimanus, Anopheles punctimacula, Bite rate, Ecuador, Malaria, Culex

\footnotetext{
*Correspondence: sjryan@ufl.edu; clippi@ufl.edu

1 Emerging Pathogens Institute, University of Florida, Gainesville, FL, USA

Full list of author information is available at the end of the article
} 


\section{Background}

Despite major efforts to control and eliminate vectorborne diseases through vector control, mosquito-borne diseases such as malaria, dengue, yellow fever, and now chikungunya and zika virus remain a major threat to people's livelihoods in the Americas. An estimated 108 million people per year are at risk for malaria infections in the Americas, pointing to a need to maintain elimination status in areas that have successfully eliminated local infections, and to prevent reestablishment [1]. In Latin America there is high endemic diversity in both vectors and pathogens, including three species of malaria-causing parasites, Plasmodium vivax, Plasmodium falciparum, and Plasmodium malariae [1-4]. To monitor and measure the potential for mosquito-borne transmission, it is important to assess the risk or rate of infectious bites on humans. There are many challenges associated with the direct surveillance of pathogens, such as Plasmodium, in mosquito populations, thus vector-borne diseases are often monitored in terms of human case data [5-7]. The reliance on human cases to monitor vector-borne disease outbreaks is subject to many forms of reporting bias, and these biases may be further exacerbated in Ecuador, where disparities in clinical access may contribute to underreporting of cases, as is seen with dengue [8-10]. Even when clinical access is more widely available, as in urban areas, much of the public health data reported by Ecuador's Ministry of Health relies on suspected clinical cases rather than laboratory confirmation [11]. Furthermore, human case data does not provide information in sufficient time to target vector control to mosquito activity. Although malaria surveillance and diagnostics in Ecuador are much stronger relative to those of other mosquito-borne diseases, detection of asymptomatic malaria and cases in remission remain a challenge to surveillance and disease elimination $[12,13]$.

Measuring force of infection, or transmission risk of mosquito-borne diseases through models of vital rates [14-17], require knowledge of many components of the transmission cycle, including biting rates. The entomological inoculation rate (EIR) is commonly used as a means of describing potential risk of infection from vector-borne diseases; this is the rate of infectious bites per person per day, usually estimated, or derived from biting rates and a measure of vector infection prevalence. EIR is considered a more direct measure of infection intensity than human incidence or other traditional epidemiological measures [18, 19]. However, in low-transmission situations, estimating sporozoite rates is stymied by large statistical error range, and thus biting rate is a better means of estimating transmission. Clearly, measuring the rate of infection in vectors can be logistically complex, but capturing an estimate of biting rate, perhaps less so. Thus, a simplified attempt to quantify potential disease transmission is the development of human bite rate (HBR) and landing rate (LR) indices, generally described as the number of mosquitoes of a species respectively exhibiting feeding or resting behaviour on a human recorded for a given location and time period [20-22]. Although used for estimating the number of female mosquitoes that are attempting to take blood meals in field or laboratory conditions, there is a great deal of variability in the literature with regards to the definitions and field protocols associated with these metrics.

A glossary of biting rate terms encountered in the literature was developed, to facilitate communication of definitions, as a means to both measure and interpret study findings for comparison (Table 1). In general, the protocol for HBR and LR studies involves an initial survey for potential sites, a species inventory to establish vector presence, training field entomology technicians in identification of species and behaviours, and establishing spatial points and temporal intervals for data collection [23]. Like raw mosquito density, HBR and LR do not directly measure infections, but these indices are often cited as a proxy for species presence, density of blood-seeking females, and the capacity for disease transmission [23, 24]. Potential issues with HBR include reliance on visual identification of mosquito species, inter-observer agreement, and exposure of workers to pathogens [25-28]. Human landing catch (HLC), wherein mosquitoes counted in the landing rate survey are captured and later examined in the lab, can overcome most of these obstacles, but at the cost of additional field and laboratory resources [22]. Depending on study design and data collection protocol, bite rate indices have the potential to provide a wealth of information regarding vector behaviour at very fine spatial and temporal scales in a manner that is both relatively cost-effective and efficient.

Ecuador's southern El Oro province (Fig. 1) has been free of locally acquired malaria infections since 2011, although the mosquito species capable of vectoring $P$. vivax and $P$. falciparum malaria are still prevalent in the area [13]. Disease surveillance and control programmes in developing countries typically suffer from limited resources in the face of high disease burden, however the Ecuadorian government has devoted a great deal of funding and logistic support to their Ministry of Health specifically for the detection and control of malaria following a resurgence of the disease in the late 1990s, which has been previously described in detail [13]. Nevertheless, with recent outbreaks of malaria occurring in other Ecuadorian provinces and neighbouring countries, the potential for re-emergence of malaria in El Oro creates a need to estimate the potential for malaria transmission as part of a surveillance system, and the behaviour 


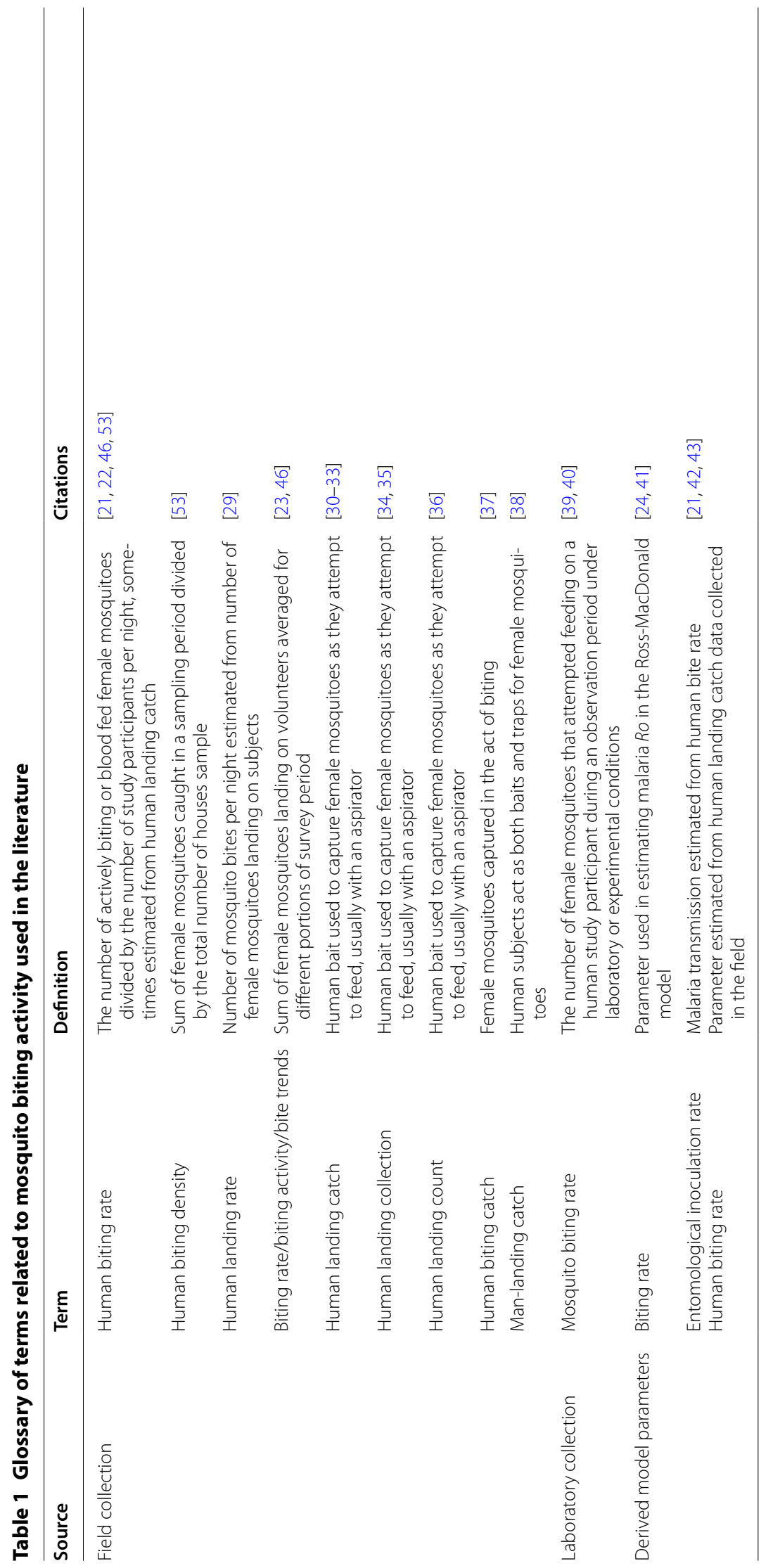




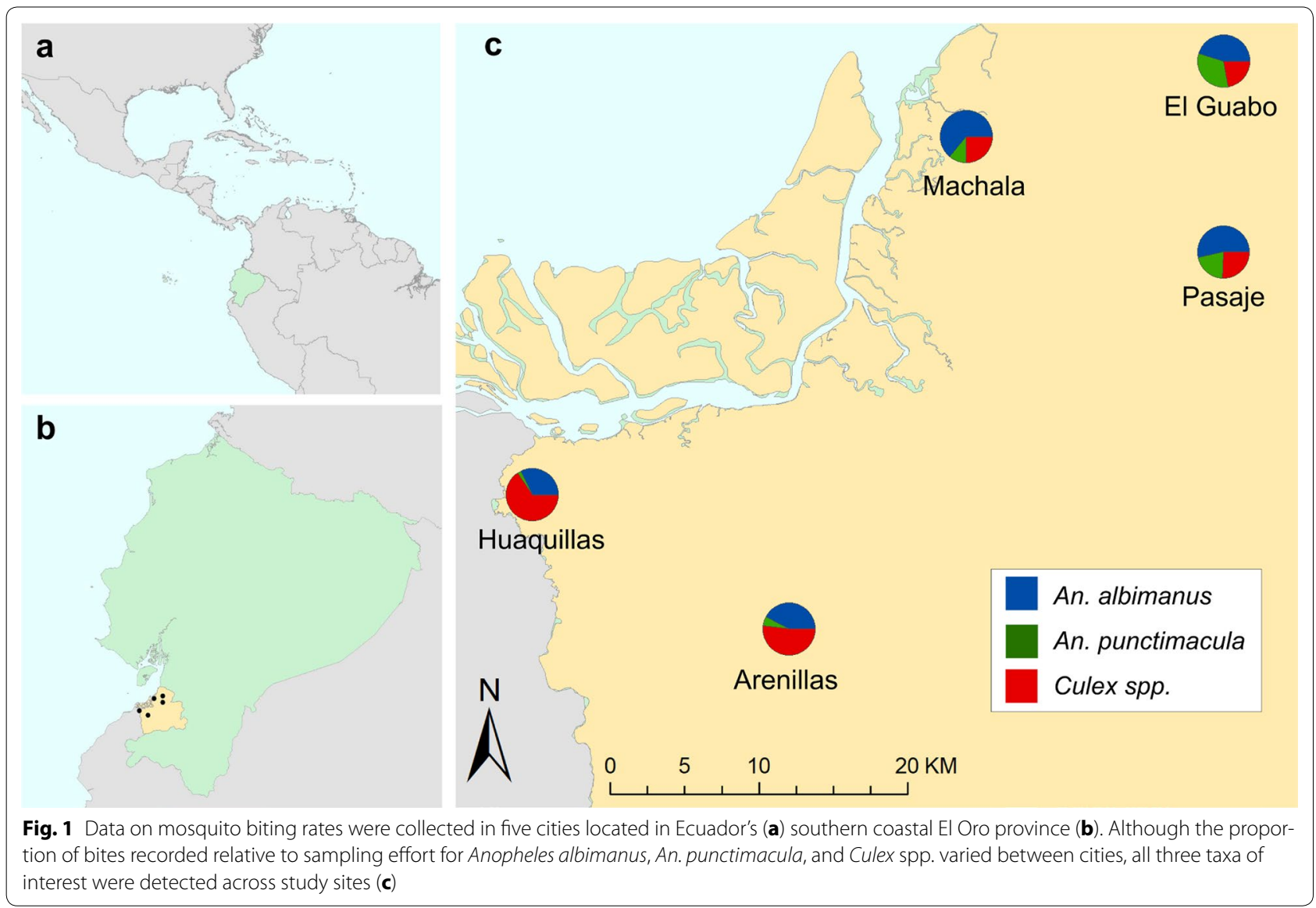

of blood-seeking female mosquitoes recorded via HLC can enhance the understanding of outbreak and exposure risks by illuminating relevant aspects of vector biology, such as seasonal activity trends by species, peak biting activity by species, detailed shifts in species composition, and host-seeking behaviour and the propensity for endophagy (indoor feeding) [44-48]. This is information that can be directly incorporated into mosquito abatement strategies, surveillance protocols, and public education campaigns.

Previous bite rate studies on Anopheles have demonstrated that mosquitoes can shift species composition and peak daily biting activity in response to abatement strategies, information that is crucial to developing and reviewing successful mosquito control efforts [21, 4951]. In Ecuador, there have been documented instances of epidemiological shifts in human disease patterns with concurrent transitions in species prevalence, and longterm collection of bite rate data at fine scales can capture these shifts [52]. This is an important consideration, as biting rate and peak biting activity are often considered as stable variables for any given species that can be directly reduced through routine interventions $[18,24,53]$.
In this study, nightly bite rate data collected in five cities from 2007 to 2012 in southern Ecuador, was examined. These data were collected as part of routine Anopheline surveillance by the National Service for the Control of Diseases Transmitted by Arthropod Vectors (SNEM) of the Ministry of Health. The goals of this paper are to (1) test the hypothesis that the bite indices for notable mosquito vectors in southern coastal Ecuador differ significantly across taxa (2) use an exploratory modelling framework to describe seasonal and diel variation in biting activity within each taxon and (3) use finescale data to compare exophagic and endophagic feeding behaviours between taxa.

\section{Methods}

\section{Bite rate data}

Human landing catch (HLC) data were collected as a proxy for the biting activity (i.e. bite rate) of two malaria vectors (Anopheles albimanus and Anopheles punctimacula) and a pooled taxonomic grouping of potential arbovirus vectors (Culex spp.) at the household level from 2007 to 2012 in five coastal cities in Ecuador's El Oro province: Huaquillas, Machala, El Guabo, Arenillas, 
and Pasaje (Fig. 1). In the first year of study, three primary sites (Huaquillas, Machala, and El Guabo) were surveyed every month to establish baseline data. In subsequent years, each site was surveyed four times annually, twice in the rainy season (January-May) and twice in the dry season. Field technicians were equipped with black stockings that covered the legs from the feet to above the knees and captured mosquitoes landing on the stockings with a mouth aspirator. Hourly collections were made each night (18:00-06:00) at study households, both inside homes and outdoors, allotting $50 \mathrm{~min}$ of each hour for aspiration and $10 \mathrm{~min}$ for specimen processing. All mosquitoes collected were brought back to the laboratory for counting, sexing, and species identification. Although sampling effort (i.e. number of survey nights) varied between cities [Arenillas $(\mathrm{n}=17)$, El Guabo $(\mathrm{n}=27)$, Huaquillas $(\mathrm{n}=38)$, Machala $(\mathrm{n}=33)$, Pasaje $(\mathrm{n}=2)]$, all three mosquito taxa were detected in all study sites (Fig. 1).

\section{Statistical analysis}

Regression models were used to determine if bite rates were fundamentally different for the three mosquito taxa, and to explore the influence of biting location (i.e. indoors vs. outdoors), season, and time of biting activity (i.e. hour of the night). Due to the size of the data set, limiting the capacity to detect city-level differences data were pooled across the five cities in the study. The bite rate data exhibited more zero observations than accommodated by commonly used error distributions for count data (e.g. Poisson or negative Binomial), an issue frequently encountered when modeling mosquito surveillance datasets, but not always treated in a statistically appropriate manner. Hurdle models were used, which combine a logistic regression model, the so-called hurdle, which describes the probability of being bitten at all, with a count model, which describes the number of bites conditional on being bitten [54]. In addition to wishing to use the appropriate statistics for the zero observations, hurdle models were also used rather than zero-inflated Poisson (ZIP) models, due to the inability to distinguish between "structural" and "sampling" zeroes in these data. In this specific case, this leads to superior interpretability, allowing for direct modelling of the probability of being bitten by a particular species.

Hurdle models were fitted using the package 'pscl' in R ver. 3.3.1 ( $\mathrm{R}$ Core Team, 2016), specifying a negative binomial error distribution and a log link for the count component, and a binomial error distribution and a logit link for the hurdle [55]. Variable selection for hurdle models was conducted based on Akaike's Information Criterion [56]. Confidence intervals for model predictions were obtained using non-parametric bootstrapping with the 'boot' package in $\mathrm{R}[57,58]$.

\section{Results}

Biting behaviour for An. albimanus, An. punctimacula, and Culex spp. differed, both in terms of whether or not bites occurred (i.e. the odds ratio (OR) of being bitten) and the number of bites/h conditional on being bitten (expressed as incidence rate ratios, RR; Table 2). Anopheles albimanus was the species most commonly observed biting (Fig. 3). The occurrence of An. albimanus bites in a given hour was four times as likely as no bites (OR $4.04, \mathrm{p}<0.001)$, with an average of 4.7 bites/h (RR 4.74, $\mathrm{p}<0.001$ ).

Being outdoors more than doubled the odds of being bitten by An. albimanus (OR 2.32, p < 0.001), and increased the number of bites received when bitten by about 50\% (RR 1.55, p < 0.001). For Culex spp. the odds of being bitten were lower overall (Fig. 3), albeit higher at the temporal reference levels of the model (i.e. January at 6 p.m.) with an odds ratio of being bitten by Culex of $13.27(\mathrm{p}<0.01)$ and an average of 6.5 bites when bitten (n.s. compared to An. albimanus). Being outdoors increased the odds of being bitten by Culex by about a third (OR 1.35, $\mathrm{p}<0.01$ ), and number of bites received by about a quarter (RR 1.22, $\mathrm{p}<0.01)$, both to a lower extent than the associated increases for An. albimanus.

Bite rates for An. punctimacula were the lowest overall (Fig. 3), with a baseline odds ratio of being bitten of 2.62 and $2.94 \mathrm{bites} / \mathrm{h}$, but these base rates did not differ significantly from those for An. albimanus. Being outdoors increased the risk of being bitten by An. albimanus by about $80 \%$ (or $1.86, \mathrm{p}<0.05$ ), and receiving bites by $40 \%$ (RR 1.40, n.s. compared to An. albimanus).

Months of peak high and low biting activity varied for the three taxa; the highest and lowest respective months for significant biting activity were March and July for $A n$.

Table 2 Species and location effects of a hurdle model of hourly biting rates

\begin{tabular}{lcc}
\hline & $\begin{array}{l}\text { Count model rate } \\
\text { ratio }\end{array}$ & Zero model odds ratio \\
\hline $\begin{array}{l}\text { Intercept (An. albi- } \\
\text { manus) }\end{array}$ & $4.74(3.05-7.36)^{* * *}$ & $4.04(2.39-6.82)^{* * *}$ \\
Culex spp. & $1.38(0.79-2.42)$ & $3.31(1.58-6.92)^{* *}$ \\
An. punctimacula & $0.6(0.31-1.18)$ & $0.65(0.31-1.36)$ \\
Location outdoors & $1.55(1.36-1.75)^{* * *}$ & $2.32(2.03-2.64)^{* * *}$ \\
Culex: outdoors & $0.79(0.66-0.94)^{* *}$ & $0.58(0.48-0.7)^{* * *}$ \\
An. puncti: outdoors & $0.9(0.71-1.13)$ & $0.8(0.66-0.97)^{*}$ \\
\hline
\end{tabular}

Model coefficients are presented as incidence rate ratios for the count model (which models hourly bites conditional on being bitten), and as odds ratios for the zero model (which models the probability of being bitten). A full table including the species-specific temporally resolved model coefficients is presented in the supplementary materials. Coefficients in this are representative for January at 6 p.m. local time and relative to An. albimanus bite rates. Values in parentheses are $95 \%$ confidence intervals. Significance levels are ${ }^{*} \mathrm{p}<0.05$, ${ }^{* *} \mathrm{p}<0.01$, *** $\mathrm{p}<0.001$ 
albimanus, July and August for An. punctimacula, and February and July for Culex spp. (Table 3).

\section{Discussion}

Using data collected during a 5 year period across five cities in southern Ecuador, temporal differences in the biting activity and endophagous versus exophagous behavior of mosquito taxa, including two species of known medical significance in Ecuador, were quantified [13, 59, 60]. Anopheles albimanus, a noted vector of malaria in Latin America, was the species most frequently observed attempting to bite human subjects, and although the baseline odds of being bitten by this species did not differ significantly from the other malaria vector, An. punctimacula, there are still distinct patterns of seasonal and temporal biting activity between the species (Tables 2, 3; Additional file 1). Despite these observed differences, all taxa demonstrated exophagic feeding tendencies-being outside of households increased the risk of exposure to mosquito bites regardless of species (Table 3).

These findings have clear implications for the delivery of mosquito abatement services and the development of public outreach programmes, as risk of exposure to mosquito bites is a demonstrated function of time (e.g. month, hour of activity), location (i.e. indoors vs. outdoors), and species of vector (Figs. 2, 3). The hot rainy season occurs from January to April, and historically, malaria season was around March-July, peaking in May [13]. Given that there was highest biting activity for An. albimanus in March, and lowest in July, but highest in July and lowest in August for An. punctimacula, the human exposure to these anopheline biting habits suggests a mix of activity level between the two species during the malaria season. For areas such as El Oro province, where malaria has been eliminated, a priori knowledge of exposure risks can be incorporated into a framework of targeted surveillance and control to prevent reemergence or reestablishment of malaria in the region. There is active vector control (household spraying) year round in Ecuador, but mosquito control efforts intensify and focus immediately before and during the rainy season (January-May), when increased water availability provides ample habitat for the aquatic larval stages of mosquitoes. Such interventions are either focused on reducing overall mosquito abundance or targeted on pooled taxonomic groupings (e.g. managing malarial infections by treating the genus Anopheles as a single group). Biting activity of the primary malaria vectors extends beyond the focal spray season-particularly An. punctimacula, which has peak activity a full 2 months after focal activity is finished. This could potentially allow additional malaria activity later in the season, and increase the role of the vector thought to be less important in Latin America. Incorporating temporal biting trends by species into management plans (i.e. peak months of biting activity) has the potential to increase the effectiveness and efficiency of mosquito control programmes by allowing decision-makers to focus resources at time periods critical to disrupting life cycles of particular vectors, and consequently the diseases they spread.

The dynamics of malaria transmission in Latin American countries are complex, and to fully understand localized disease risks, exposure to vectors and also the vectorial capacity of mosquitoes, must be examined, which can vary with species and environment [61-63]. That said, quantifying taxonomic-specific biting patterns is still a useful endeavour when developing

Table 3 Predicted average nightly bite rates (bites/hour) and associated $95 \%$ confidence intervals

\begin{tabular}{|c|c|c|c|c|c|c|}
\hline \multirow[t]{2}{*}{ Month } & \multicolumn{2}{|l|}{ An. albimanus } & \multicolumn{2}{|c|}{ An. punctimacula } & \multicolumn{2}{|l|}{ Culex spp. } \\
\hline & Indoors & Outdoors & Indoors & Outdoors & Indoors & Outdoors \\
\hline Jan & $4.85(2.57-8.01)$ & $8.06(4.98-12.52)$ & $3.59(1.53-6.06)$ & $5.26(2.51-8.69)$ & $9.28(5.85-11.99)$ & $11.31(7.34-14.64)$ \\
\hline Feb & $1.93(0.78-3.58)$ & $3.73(1.84-6.32)$ & $0.68(0.19-1.27)$ & $1.29(0.38-2.37)$ & $8.12(5.28-10.43)$ & $9.8(6.51-12.63)$ \\
\hline Mar & $9.73(5.42-15.88)$ & $15.96(10.05-24.75)$ & $1.03(0.34-1.77)$ & $1.69(0.64-2.85)$ & $2.69(1.33-3.8)$ & $3.45(1.8-4.69)$ \\
\hline Apr & $3.3(1.66-5.54)$ & $5.6(3.34-8.78)$ & $0.38(0.11-0.68)$ & $0.71(0.21-1.28)$ & $3.89(2.24-5.01)$ & $4.81(2.9-6.13)$ \\
\hline May & $3.13(1.6-5.21)$ & $5.26(3.18-8.19)$ & $0.07(0.03-0.11)$ & $0.13(0.05-0.18)$ & $0.93(0.39-1.49)$ & $1.23(0.55-1.9)$ \\
\hline Jun & $5.31(3.18-8.29)$ & $8.31(5.5-12.48)$ & $0.24(0.08-0.4)$ & $0.43(0.14-0.72)$ & $4.4(2.93-5.54)$ & $5.25(3.58-6.63)$ \\
\hline Jul & $2.85(1.49-4.67)$ & $4.71(2.9-7.24)$ & $1.69(0.78-2.67)$ & $2.39(1.24-3.72)$ & $0.77(0.35-1.18)$ & $0.99(0.47-1.46)$ \\
\hline Aug & $1.69(0.65-3.22)$ & $3.38(1.59-5.88)$ & $0.58(0.17-1.05)$ & $1.06(0.33-1.9)$ & $2.47(1.19-3.53)$ & $3.18(1.63-4.38)$ \\
\hline Sep & $7.27(3.56-12.53)$ & $12.68(7.41-20.35)$ & $1.87(0.53-3.52)$ & $3.34(1.08-6.11)$ & $3.35(1.6-4.8)$ & $4.35(2.2-5.99)$ \\
\hline Oct & $6.59(3.44-11.02)$ & $11.1(6.77-17.44)$ & $2.98(0.71-6.01)$ & $5.88(1.56-11.54)$ & $1.24(0.57-1.87)$ & $1.6(0.78-2.33)$ \\
\hline Nov & $3.14(1.38-5.63)$ & $5.77(3.09-9.51)$ & $1.32(0.33-2.59)$ & $2.58(0.71-4.95)$ & $3.32(1.7-4.57)$ & $4.23(2.28-5.61)$ \\
\hline Dec & $1.9(0.95-3.15)$ & $3.19(1.9-4.93)$ & $1.06(0.37-1.79)$ & $1.69(0.68-2.79)$ & $2.16(0.83-3.6)$ & $2.99(1.21-4.8)$ \\
\hline
\end{tabular}



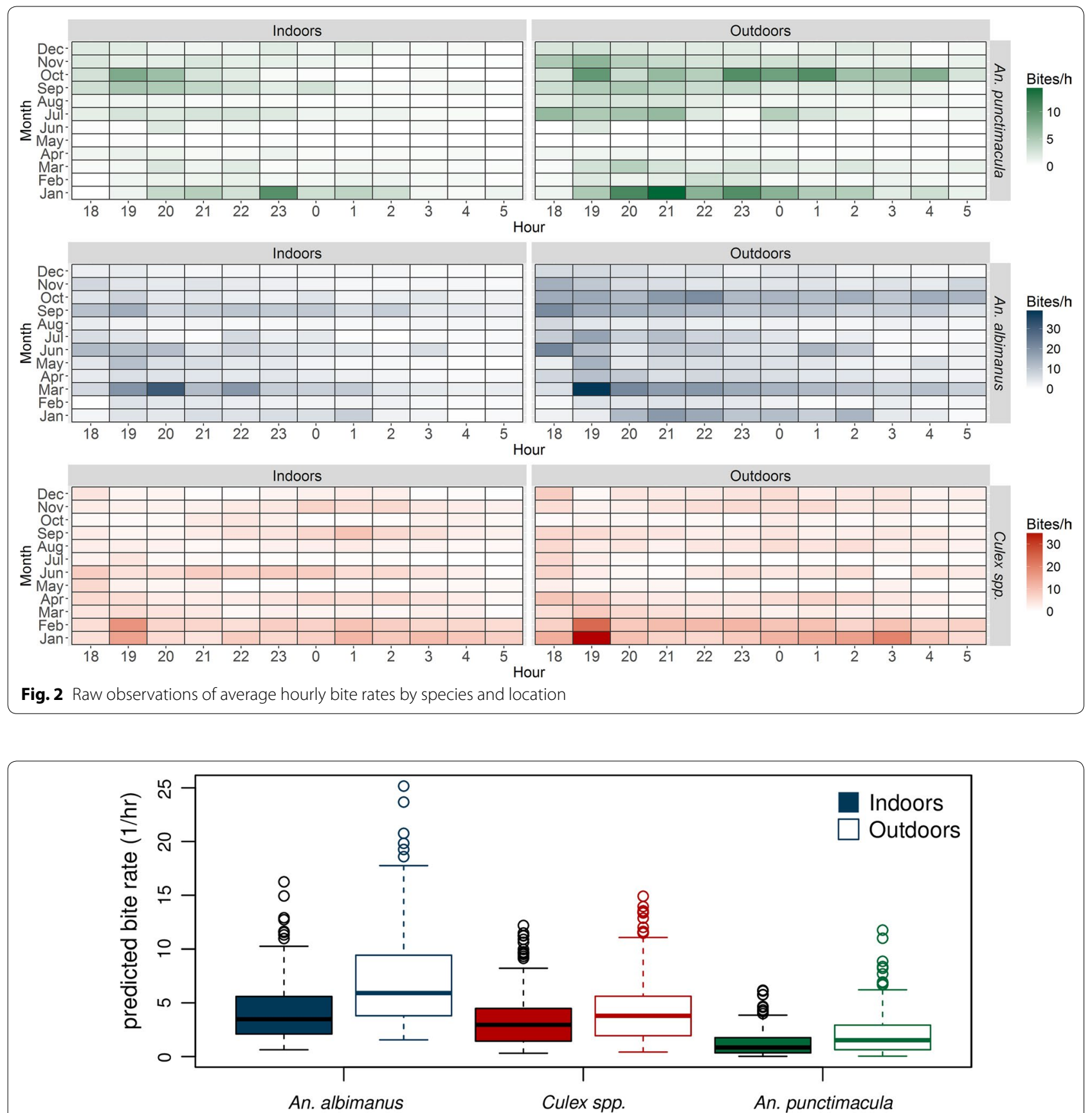

Fig. 3 Hourly bite rates by species and location as predicted by the hurdle model across all months and hours of the night

control strategies, as demonstrably competent disease vectors are known to display differential feeding behaviours throughout their geographic ranges. This is the case with An. albimanus, which has been observed displaying both anthropophilic and zoophilic feeding preferences depending on location, potentially responsible for spatial variability in the true risk of disease transmission to humans $[2,64-66]$. Similarly, patterns of microhabitat use can vary spatially, with the proportion of endophagic versus exophagic mosquitoes depending not only on taxon, but also spatially contextual factors such as environment and housing structures [47, 66]. In these instances, the collection of HLC data can serve as a better indicator of true exposure risk than simply documenting the presence of known competent vectors. 
The utility of bite rate indices as a relatively low-cost surveillance tool is well documented [22, 23, 65]. However, the ability to differentiate closely related mosquito species may serve as an additional logistical challenge to the field surveillance of mosquito vectors in Ecuador. Female An. punctimacula are morphologically similar to Anopheles calderoni, another vector of malaria in Latin America [67]. Despite being a competent vector of Plasmodium spp., An. calderoni was only recently confirmed in several Latin American countries, including Ecuador, due to the systematic misclassification of the species [67, 68]. The potential for misidentification of these taxa on surveys may obscure true species-level patterns in biting activity. Given the combination of later season biting activity, and potential misidentification, this warrants future work.

The bite count data in this study were collected at a very high temporal (e.g. hourly) and behavioural level (e.g. inside and outside of households) resolutions but were pooled across the five study cities for statistical analysis. This was largely due to the high number of variable combinations (e.g. species by month, species by hour) relative to the number of collection nights and the inherent zero-inflated nature of count data. Ideally, future studies would strive for more spatio-temporally balanced data collection across cities, allowing for more robust exploration of the larger spatial variation (intercity) in biting trends across the study region. This would involve deploying multiple trained teams, which may be a prohibitive constraint at present. Despite these limitations, human bite rate indices remain a valuable tool in the collection of high-resolution vector ecology data, enabling quantification of risks associated with exposure to mosquito bites in a manner that is cost-effective and simple to implement.

\section{Conclusions}

This is the first time that fine-scale behavioural (endophagy and exophagy) and temporal differences in the biting patterns of mosquito taxa have been reported for El Oro province in southern coastal Ecuador. These findings provide detailed information for targeting vector control and household level prevention strategies. Quantifying hourly and seasonal biting activity, and examining endo- and exophagous behaviours are important to allocating resources and strategies appropriately. The data used to examine human biting trends were collected as part of routine vector surveillance conducted by the Ministry of Health, but such data have not been collected since the end of this dataset. As seen with dengue in the region, even when there is decline in cases, as happened prior to the 1970s, relaxing vector control, and reducing surveillance, can lead to rapid reemergence. Reinstating such surveillance measures will provide important information that will aid in preventing malaria re-emergence.

\section{Additional file}

Additional file 1: Table S1. Hurdle model of hourly biting rates. Model coefficients are presented as incidence rate ratios for the count model (which models hourly bites conditional on being bitten using a negative binomial error distribution and log link), and as odds ratios for the zero model (which models the probability of being bitten using binomial errors and a logit link). Values in parentheses are $95 \%$ confidence intervals. Significance levels are ${ }^{*} p<0.05,{ }^{* *} p<0.01,{ }^{* * *} p<0.001$.

\section{Abbreviations}

HLC: human landing catch; EIR: entomological inoculation rate; HBR: human biting rate; LR: landing rate; SNEM: National Service for the Control of Diseases Transmitted by Arthropod Vectors (Ecuador); OR: odds ratio; RR: rate ratio.

\section{Authors' contributions}

AMS, MS, EBA conceived the project and designed the surveys. SJR, CAL, PHBS conducted statistical analyses and prepared figures and maps. SJR, CAL, PHBS drafted the manuscript. LK, JTK, JA, MS contributed to the development of the database. SJR, CAL, PHBS, NH, MS, JA, LFN, EBA, ME, DA, JTK, LK, LF, and AMS contributed to the final version of the manuscript. All authors read and approved the final manuscript.

\section{Author details}

${ }^{1}$ Emerging Pathogens Institute, University of Florida, Gainesville, FL, USA. ${ }^{2}$ Department of Geography, University of Florida, Gainesville, FL, USA. ${ }^{3}$ Center for Global Health and Translational Science and Department of Medicine, State University of New York Upstate Medical University, Syracuse, NY, USA. ${ }^{4}$ College of Agriculture, Engineering, and Science, University of KwaZulu-Natal, Durban, South Africa. ${ }^{5}$ Department of Integrative Biology, University of South Florida, Tampa, FL, USA. ${ }^{6}$ Laboratorio Clínico Hospital Teófilo Dávila, Ministerio de Salud Pública, Machala, Ecuador. ${ }^{7}$ Lab. Entomologia CZ7, Ministerio de Salud Pública, Machala, Ecuador. ${ }^{8}$ Facultad de Medicina, Universidad Técnica de Machala, Machala, Ecuador. ${ }^{9}$ Dirección Nacional de Vigilancia Epidemiológica, Ministerio de Salud Pública, Av. República de El Salvador 36-64 y Suecia, 170515 Quito, Ecuador. ${ }^{10}$ Department of Public Health, Food Studies, and Nutrition, Syracuse University, Syracuse, NY, USA. ${ }^{11}$ Division of Nutritional Sciences, Cornell University, Ithaca, NY, USA. ${ }^{12}$ Center for Health, Work \& Environment, Department of Environmental and Occupational Health, Colorado School of Public Health, University of Colorado Denver, Aurora, CO, USA.

${ }^{13}$ Colorado Consortium on Climate Change and Human Health, University of Colorado Denver, Aurora, CO, USA.

\section{Acknowledgements}

We thank the Ministry of Health, SNEM, and the vector teams who contributed to this study. We thank the people of Huquillas, Arenilla, El Guabo, Pasaje, and Machala for participating in the original surveillance work.

\section{Competing interests}

The authors declare that they have no competing interests.

\section{Availability of data and materials}

The original datasets analysed during the current study are not publicly available, as they belong to SNEM-National Service for the Control of Diseases Transmitted by Arthropod Vectors, and the Ministry of Health, of Ecuador. Derived datasets are available on request from the corresponding author.

\section{Consent for publication}

Not applicable.

Ethics approval and consent to participate Not applicable. 


\section{Funding}

Analyses and writing by SJR, AMS, CAL, and LF were supported by NSF DEB-1518681, and SJR and AMS by NSF DEB-1641145, and SJR by CDC grant 1U01CK000510-01: Southeastern Regional Center of Excellence in VectorBorne Diseases: the Gateway Program. This publication was supported by the Cooperative Agreement Number above from the Centers for Disease Control and Prevention. Its contents are solely the responsibility of the authors and do not necessarily represent the official views of the Centers for Disease Control and Prevention.

\section{Publisher's Note}

Springer Nature remains neutral with regard to jurisdictional claims in published maps and institutional affiliations.

Received: 8 August 2017 Accepted: 14 November 2017 Published online: 22 November 2017

\section{References}

1. Pan American Health Organization. Report on the situation of malaria in the Americas, 2014. Washington DC: PAHO; 2016. p. 114.

2. Sinka ME, Rubio-Palis Y, Manguin S, Patil AP, Temperley WH, Gething PW, et al. The dominant Anopheles vectors of human malaria in the Americas: occurrence data, distribution maps and bionomic précis. Parasites Vectors. 2010;3:72

3. Cruz LR, Spangenberg T, Lacerda MV, Wells TN. Malaria in South America: a drug discovery perspective. Malar J. 2013;12:168.

4. CDC. Health Information for Travelers to Ecuador, Including the Galapages Islands [Internet]. Centers for Disease Control; 2016. http://wwwnc. cdc.gov/travel/destinations/traveler/none/ecuador. Accessed 1 Dec 2016

5. WHO, Global Malaria Programme. Disease surveillance for malaria control: an operational manual. Geneva: World Health Organization; 2012. http:// apps.who.int/iris/bitstream/10665/44851/1/9789241503341_eng.pdf. Accessed 9 May 2016.

6. Guedes DRD, Cordeiro MT, Melo-Santos MAV, Magalhaes T, Marques E, Regis L, et al. Patient-based dengue virus surveillance in Aedes aegypti from Recife, Brazil. J Vector Borne Dis. 2010;47:67-75.

7. Flies EJ, Toi C, Weinstein P, Doggett SL, Williams CR. Converting mosquito surveillance to arbovirus surveillance with honey-baited nucleic acid preservation cards. Vector Borne Zoonotic Dis. 2015;15:397-403.

8. Lopez-Cevallos D, Chi C. Inequity in health care utilization in Ecuador: an analysis of current issues and potential solutions. Int J Equity Health. 2012;11:A6

9. Stewart-lbarra AM, Muñoz ÁG, Ryan SJ, Ayala EB, Borbor-Cordova MJ, Finkelstein $\mathrm{J}$, et al. Spatiotemporal clustering, climate periodicity, and social-ecological risk factors for dengue during an outbreak in Machala, Ecuador, in 2010. BMC Infect Dis. 2014;14:610.

10. Dumonteil E, Herrera C, Martini L, Grijalva MJ, Guevara AG, Costales JA, et al. Chagas disease has not been controlled in Ecuador. PLoS ONE. 2016;11:e0158145.

11. Stewart Ibarra AM, Ryan SJ, Beltrán E, Mejía R, Silva M, Muñoz Á. Dengue vector dynamics (Aedes aegypti) influenced by climate and social factors in Ecuador: implications for targeted control. PLOS ONE. 2013;8:e78263.

12. Sturrock HJW, Hsiang MS, Cohen JM, Smith DL, Greenhouse B, Bousema T, et al. Targeting asymptomatic malaria infections: active surveillance in control and elimination. PLoS Med. 2013;10:e1001467.

13. Krisher LK, Krisher J, Ambuludi M, Arichabala A, Beltrán-Ayala E, Navarrete $P$, et al. Successful malaria elimination in the Ecuador? Peru border region: epidemiology and lessons learned. Malar J. 2016;15:573.

14. Mordecai EA, Paaijmans KP, Johnson LR, Balzer C, Ben-Horin T, de Moor E, et al. Optimal temperature for malaria transmission is dramatically lower than previously predicted. Ecol Lett. 2013;16:22-30.

15. Ross R. Some a priori pathometric equations. BMJ. 1915;1:546-7.

16. MacDonald G. The epidemiology and control of malaria. 1957. p. $x v+201+x l+11$

17. Mordecai EA, Cohen JM, Evans MV, Gudapati P, Johnson LR, Lippi CA, et al. Detecting the impact of temperature on transmission of Zika, dengue, and chikungunya using mechanistic models. PLoS Negl Trop Dis. 2017;11:e0005568.

18. Smith DL, McKenzie FE. Statics and dynamics of malaria infection in Anopheles mosquitoes. Malar J. 2004;3:13.

19. Kelly-Hope LA, McKenzie FE. The multiplicity of malaria transmission: a review of entomological inoculation rate measurements and methods across sub-Saharan Africa. Malar J. 2009;8:19.

20. Kang S-H. Comparative repellency of essential oils against Culex pipiens pallens (Diptera: Culicidae). J Korean Soc Appl Biol Chem. 2009;52:353-9.

21. Mutuku FM, King CH, Mungai P, Mbogo C, Mwangangi J, Muchiri EM, et al. Impact of insecticide-treated bed nets on malaria transmission indices on the south coast of Kenya. Malar J. 2011;10:356.

22. Overgaard HJ, Sæbø S, Reddy MR, Reddy VP, Abaga S, Matias A, et al. Light traps fail to estimate reliable malaria mosquito biting rates on Bioko Island, Equatorial Guinea. Malar J. 2012;11:56.

23. Korgaonkar NS, Kumar A, Yadav RS, Kabadi D, Dash AP. Mosquito biting activity on humans \& detection of Plasmodium falciparum infection in Anopheles stephensi in Goa, India. Indian J Med Res. 2012:135:120-6.

24. Bellan SE. The importance of age dependent mortality and the extrinsic incubation period in models of mosquito-borne disease transmission and control. PLOS ONE. 2010;5:e10165.

25. Onyango SA, Kitron U, Mungai P, Muchiri EM, Kokwaro E, King CH, et al. Monitoring malaria vector control interventions: effectiveness of five different adult mosquito sampling methods. J Med Entomol. 2013;50:1140-51.

26. WHO. Malaria entomology and vector control guide for participants. Geneva: World Health Organization; 2013.

27. Sikaala CH, Killeen GF, Chanda J, Chinula D, Miller JM, Russell TL, et al. Evaluation of alternative mosquito sampling methods for malaria vectors in Lowland South-East Zambia. Parasites Vectors. 2013;6:91

28. Kenea O, Balkew M, Tekie H, Gebre-Michael T, Deressa W, Loha E, et al. Comparison of two adult mosquito sampling methods with human landing catches in south-central Ethiopia. Malar J. 2017;16:30.

29. Burkot TR, Russell TL, Reimer LJ, Bugoro H, Beebe NW, Cooper RD, et al. Barrier screens: a method to sample blood-fed and host-seeking exophilic mosquitoes. Malar J. 2013;12:49.

30. Mathenge EM, Omweri GO, Irungu LW, Ndegwa PN, Walczak E, Smith TA, et al. Comparative field evaluation of the Mbita trap, the Centers for Disease Control light trap, and the human landing catch for sampling of malaria vectors in western Kenya. Am J Trop Med Hyg. 2004;70:33-7.

31. Govella NJ, Chaki PP, Geissbuhler Y, Kannady K, Okumu F, Charlwood JD, et al. A new tent trap for sampling exophagic and endophagic members of the Anopheles gambiae complex. Malar J. 2009;8:157.

32. Okumu FO, Kotas ME, Kihonda J, Mathenge E, Killeen GF, Moore SJ. Comparative evaluation of methods used for sampling malaria vectors in the kilombero valley, South Eastern Tanzania. Open Trop Med J. 2008;1:51-5.

33. Fornadel CM, Norris LC, Norris DE. Centers for disease control light traps for monitoring Anopheles arabiensis human biting rates in an area with low vector density and high insecticide-treated bed net use. Am J Trop Med Hyg. 2010;83:838-42.

34. Mani TR, Arunachalam N, Rajendran R, Satyanarayana K, Dash AP. Efficacy of thermal fog application of deltacide, a synergized mixture of pyrethroids, against Aedes aegypti, the vector of dengue: Deltacide fog against Aedes aegypti. Trop Med Int Health. 2005;10:1298-304.

35. Hiwat H, Andriessen R, Rijk M de, Koenraadt CJM, Takken W. Carbon dioxide baited trap catches do not correlate with human landing collections of Anopheles aquasalis in Suriname. Mem Inst Oswaldo Cruz. 2011;106:360-4.

36. Obenauer PJ, Kaufman PE, Kline DL, Allan SA. Detection of and monitoring for Aedes albopictus (Diptera: Culicidae) in Suburban and sylvatic habitats in North Central Florida using four sampling techniques. Environ Entomol. 2010;39:1608-16.

37. Magbity EB, Magbity EB, Lines JD, Marbiah MT, David K, Peterson E. How reliable are light traps in estimating biting rates of adult Anopheles gambiae s.l. (Diptera: Culicidae) in the presence of treated bed nets? Bull Entomol Res. 2002;92:71-6.

38. Canyon DV, Hii JL. Efficacy of carbon dioxide, 1-octen-3-ol, and lactic acid in modified Fay-Prince traps as compared to man-landing catch of Aedes aegypti. J Am Mosq Control Assoc. 1997;13:66-70.

39. Barnard DR, Posey KH, Smith D, Schreck CE. Mosquito density, biting rate and cage size effects on repellent tests. Med Vet Entomol. 1998;12:39-45. 
40. Kitau J, Pates H, Rwegoshora TR, Rwegoshora D, Matowo J, Kweka EJ, et al. The effect of mosquito Magnet ${ }^{\circledR}$ liberty plus trap on the human mosquito biting rate under semi-field conditions. J Am Mosq Control Assoc. 2010;26:287-94.

41. Roitberg BD, Mangel M. Mosquito biting and movement rates as an emergent community property and the implications for malarial interventions. Isr J Ecol Evol 2010;56:297-312.

42. Beier JC, Killeen GF, Githure Jl. Short report: entomologic inoculation rates and Plasmodium falciparum malaria prevalence in Africa. Am J Trop Med Hyg. 1999;61:109-13.

43. Kilama M, Smith DL, Hutchinson R, Kigozi R, Yeka A, Lavoy G, et al. Estimating the annual entomological inoculation rate for Plasmodium falciparum transmitted by Anopheles gambiae s.l. using three sampling methods in three sites in Uganda. Malar J. 2014;13:111.

44. Herrera-Varela M, Orjuela LI, Peñalver C, Conn JE, Quiñones ML. Anopheles species composition explains differences in Plasmodium transmission in La Guajira, northern Colombia. Mem Inst Oswaldo Cruz. 2014;109:952-6.

45. Loaiza JR, Bermingham E, Scott ME, Rovira JR, Conn JE. Species composition and distribution of adult Anopheles (Diptera: Culicidae) in Panama. J Med Entomol. 2008;45:841-51.

46. Vittor AY, Gilman RH, Tielsch J, Glass GE, Shields T, Lozano WS, et al. The effect of deforestation on the human-biting rate of Anopheles darlingi, the primary vector of falciparum malaria in the Peruvian Amazon. Am J Trop Med Hyg. 2006;74:3-11.

47. Hobbs JH, Sexton JD, St Jean Y, Jacques JR. The biting and resting behavior of Anopheles albimanus in northern Haiti. J Am Mosq Control Assoc. 1986;2:150-3.

48. Sáenz FE, Morton LC, Okoth SA, Valenzuela G, Vera-Arias CA, Vélez-Álvarez E, et al. Clonal population expansion in an outbreak of Plasmodium falciparum on the northwest coast of Ecuador. Malar J. 2015;14:497.

49. Russell TL, Govella NJ, Azizi S, Drakeley CJ, Kachur SP, Killeen GF. Increased proportions of outdoor feeding among residual malaria vector populations following increased use of insecticide-treated nets in rural Tanzania. Malar J. 2011;10:80.

50. Sougoufara S, Diédhiou SM, Doucouré S, Diagne N, Sembène PM, Harry $M$, et al. Biting by Anopheles funestus in broad daylight after use of longlasting insecticidal nets: a new challenge to malaria elimination. Malar J. 2014;13:125.

51. Lindblade KA, Gimnig JE, Kamau L, Hawley WA, Odhiambo F, Olang G, et al. Impact of sustained use of insecticide-treated bednets on malaria vector species distribution and Culicine mosquitoes. J Med Entomol. 2006;43:428-32.

52. Cifuentes SG, Trostle J, Trueba G, Milbrath M, Baldeón ME, Coloma J, et al. Transition in the cause of fever from malaria to dengue, Northwestern Ecuador, 1990-2011. Emerg Infect Dis. 2013;19:1642-5.

53. Kabbale FG, Akol AM, Kaddu JB, Onapa AW. Biting patterns and seasonality of Anopheles gambiae sensu lato and Anopheles funestus mosquitoes in Kamuli District, Uganda. Parasites Vectors. 2013;6:340.
54. Zeileis A, Kleiber C, Jackman S. Regression models for count data in R. J Stat Softw. 2008;27:33378.

55. Jackman S. pscl: classes and methods for R developed in the political science computational library. Stanford: Stanford University; 2015.

56. Burnham KP, Anderson DR, Burnham KP. Model selection and multimodel inference: a practical information-theoretic approach. 2nd ed. New York: Springer; 2002.

57. Davison AC, Hinkley DV. Bootstrap methods and their application. New York: Cambridge University Press; 1997.

58. Canty A, Ripley B. Boot: Bootstratp R (S-Plus) functions. 2017.

59. Pinault LL, Hunter FF. Characterization of larval habitats of Anopheles albimanus, Anopheles pseudopunctipennis, Anopheles punctimacula, and Anopheles oswaldoi s.l. populations in lowland and highland Ecuador. J Vector Ecol. 2012;37:124-36.

60. Rubio-Palis Y, Zimmerman RH. Ecoregional classification of malaria vectors in the neotropics. J Med Entomol. 1997;34:499-510.

61. Turell MJ. Effect of environmental temperature on the vector competence of Aedes taeniorhynchus for Rift Valley fever and Venezuelan equine encephalitis viruses. Am J Trop Med Hyg. 1993;49:672-6.

62. Okech BA, Gouagna LC, Yan G, Githure JI, Beier JC. Larval habitats of Anopheles gambiae s.s. (Diptera: Culicidae) influences vector competence to Plasmodium falciparum parasites. Malar J. 2007;6:50.

63. Antonio-nkondjio C, Kerah CH, Simard F, Awono-ambene P, Chouaibou $\mathrm{M}$, Tchuinkam T, et al. Complexity of the malaria vectorial system in cameroon: contribution of secondary vectors to malaria transmission. J Med Entomol. 2006:43:1215-21.

64. Loyola EG, González-Cerón L, Rodríguez MH, Arredondo-Jiménez Jl, Bennett S, Bown DN. Anopheles albimanus (Diptera: Culicidae) host selection patterns in three ecological areas of the coastal plains of Chiapas, southern Mexico. J Med Entomol. 1993;30:518-23.

65. Solarte Y, Hurtado C, Gonzalez R, Alexander B. Man-biting activity of Anopheles (Nyssorhynchus) albimanus and An. (Kerteszia) neivai (Diptera: Culicidae) in the Pacific lowlands of Colombia. Mem Inst Oswaldo Cruz. 1996;91:141-6

66. Bown DN, Rodriguez MH, Arredondo-Jimenez JI, Loyola EG, Rodriguez MC. Intradomiciliary behavior of Anopheles albimanus on the coastal plain of southern Mexico: implications for malaria control. J Am Mosq Control Assoc. 1993:9:321-4.

67. González R, Carrejo N, Wilkerson RC, Alarcon J, Alarcon-Ormasa J, Ruiz F, et al. Confirmation of Anopheles (Anopheles) calderoni Wilkerson, 1991 (Diptera: Culicidae) in Colombia and Ecuador through molecular and morphological correlation with topotypic material. Mem Inst Oswaldo Cruz. 2010;105:1001-9.

68. Orjuela LI, Ahumada ML, Avila I, Herrera S, Beier JC, Quiñones ML. Human biting activity, spatial-temporal distribution and malaria vector role of Anopheles calderoni in the southwest of Colombia. Malar J. 2015;14:256.

\section{Submit your next manuscript to BioMed Central and we will help you at every step:}

- We accept pre-submission inquiries

- Our selector tool helps you to find the most relevant journal

- We provide round the clock customer support

- Convenient online submission

- Thorough peer review

- Inclusion in PubMed and all major indexing services

- Maximum visibility for your research

Submit your manuscript at www.biomedcentral.com/submit
BioMed Central 